\title{
EDITORIAL
}

\section{Bipolar-spectrum disorders: an epidemic unseen, invisible or unreal?}

\author{
Zubin Bhagwagar \& Guy M. Goodwin
}

Major depression is a common and disabling condition, which has been listed as one of the leading causes of morbidity by the World Health Organization (Murray \& Lopez, 1997b); it is estimated that by the year 2020 major depression will be second only to ischaemic heart disease in terms of the leading causes of morbidity in the world and will be the leading cause in developing regions (Murray \& Lopez, 1997a). As pointed out by Smith \& Blackwood (2004) later in this issue, the disorder is multi-faceted with varied pathophysiology and often presents in early adulthood. Although early recognition and treatment are important in any illness, there is an added twist to the issue of accurate diagnosis. The problem is not major depression, the definition of which is not particularly contentious, but the recognition of associated states of elation and the status of bipolar-spectrum disorders (Akiskal et al, 2000).

Bipolar disorder has long been synonymous in the minds of psychiatrists with manic-depressive disorder. However, the latter term was derived from Kraepelin's 'manic depressive insanity', which grouped together all severe affective psychoses, unipolar and bipolar. The emphasis on bipolarity emerged relatively recently, and with it the possibility that bipolarity might have minor as well as major forms. Although there is little controversy surrounding the definition of bipolar I disorder (episodes of mania and depression) there is probably widespread lack of understanding of what minor bipolar disorder is and how commonly it occurs. The DSM-IV (American Psychiatric Association, 1994) provides one answer. Large-scale epidemiological studies such as the National Comorbidity Survey (Kessler et al, 1997) have reported a prevalence rate of bipolar I disorder of about $0.5 \%$. The DSM-IV states that symptoms of mood elevation, sufficient to produce functional impairment, are required for a minimum of 7 days (or to hospitalisation) to warrant a diagnosis of a manic episode. Symptoms of elation lasting for at least 4 days but with no impairment should be diagnosed as hypomania. Hypomania with major depression defines bipolar II disorder in DSM-IV. Defined thus, bipolar II disorder also has a prevalence of $0.5 \%$ (Regier et al, 1990).

\section{Diagnosis of hypomania}

The diagnosis of hypomania poses further problems. First, there is a growing movement to simply lower the admittedly arbitrary time criterion for hypomania. When this criterion was reduced to 2 days, the number of cases of bipolar II disorder increased nearly ten-fold in the Zurich cohort (Angst, 1998) with a total rate for 'bipolar disorder' of $5.5 \%$. It has been tentatively suggested that cases of brief hypomania and major depression should be given a diagnosis of bipolar III disorder, but this has not been widely adopted.

Second, symptoms of mood elevation may not be severe enough to satisfy the DSM-IV checklist, yet they are still recorded in patient interviews. Some authors believe this to imply that a further radical inflation of the bipolar spectrum is required to capture accurately all patients with 'the disorder' (Angst, 1998; Perugi et al, 1998; Akiskal et al, 2000; Benazzi \& Akiskal, 2003). Softening the criteria still further will increase the rate of bipolar diagnoses to about $50 \%$ of 'unipolar' cases of depression.

Zubin Bhagwagar is a clinical lecturer in psychiatry at the Department of Psychiatry, University of Oxford. He has a special interest in the pathophysiology of bipolar disorder with an emphasis on novel neuroimaging techniques. Guy Goodwin is W.A. Handley Professor of Psychiatry at the University of Oxford (University Department of Psychiatry, Warneford Hospital, Oxford OX3 7JX, UK. E-mail: guy.goodwin@psychiatry.oxford.ac.uk). His research interests are the treatment of severe psychiatric illness and the application of neuroscience to the neurobiology of mood disorder. He is involved in projects on the neurobiology and genetics of vulnerability to mood disorder, the neuropsychology of bipolar disorder and the psychological mechanisms of psychotropic medicines. He is also developing a large-scale pragmatic clinical trial in bipolar affective disorder (BALANCE). 
Third, the term 'hypomania' is misused widely to describe mania itself. This is a curious phenomenon (Goodwin, 2002), but can no doubt be overcome. However, it means that many clinicians are, in effect, blind to bipolar II disorder as currently defined. Therefore, patients with bipolar II disorder are often misdiagnosed as having unipolar depression. The prevalence of bipolar II disorder in samples of patients thought to have unipolar depression has been reported to be as high as $40 \%$ (Akiskal \& Mallya, 1987; Benazzi, 1998; Hantouche et al, 1998; Perugi et al, 1998; Ghaemi et al, 2000).

None of this would matter greatly if the distinction between bipolar and unipolar disorders had no implication for treatment. However, Ghaemi found that antidepressants were used earlier and more frequently than mood stabilisers in patients with bipolar II disorder, and that almost a quarter of patients experienced a new or worsening rapidcycling course attributable to antidepressant prescription (Ghaemi et al, 2000). This is the nub of the issue. Do patients with major depression and a personal history of minor elated states require a treatment for their depression different from that for truly unipolar major depression? There can be little doubt that some patients are currently ill-served by the failure to detect past or current mood elevation, but the scale and severity of the problem have yet to be definitively established.

\section{Bipolar disorder in children}

Smith \& Blackwood (2004, this issue) also reflect on an unrelated debate regarding paediatric bipolar disorder. Its existence has been questioned (Carlson, 1998; Biederman, 2003), with a British epidemiological study finding no case of mania among preadolescent children (Meltzer et al, 2000). The contrast with North American enthusiasm for bipolar diagnoses in children is striking (Weller et al, 1986). The 'early' diagnosis of pre-pubertal mania seems to require that inferences are made about the meaning of some non-specific behaviours and it is difficult to see how such diagnoses can be reliable (Harrington \& Myatt, 2003). Only prospective follow-up studies will establish the adult validity of childhood diagnoses.

A major confound is the alleged comorbidity of childhood bipolar disorder with attention-deficit hyperactivity disorder (Biederman et al, 1998). Attention-deficit hyperactivity disorder (ADHD) is probably underdiagnosed in Europe and overdiagnosed in North America. The symptoms seem to co-mingle with those of paediatric bipolar disorder, probably fatally for reliable differential diagnosis. However, the treatment of ADHD with stimulants may have the potential to induce elated states in children. Is it possible that the widespread use of stimulants to treat difficult behaviour in children accounts for the apparent epidemic of paediatric bipolar disorder in North America?

Early recognition and treatment of conditions such as depression or bipolar disorder in young adults may be desirable but the diagnosis must be reliable. Just as paediatric bipolar definitions extend the boundaries of the disorder in children, there must be concern about the widening of the definitions of bipolar disorder described in adults. The risk may be that diluting the concept will lead to a trivialisation of the disorder (Baldessarini, 2000).

\section{A neglected disease}

There is a sense in which these controversies are welcome, whatever the ultimate outcome, because they raise the profile of a neglected disease. Objectively, there has been much less research activity in bipolar disorder than in schizophrenia (Clement et al, 2003).

There was even a strange paucity of references to bipolar disorder in the National Service Framework for Mental Health (Department of Health, 1999) - could this have been because it fails to conform to the social model of a 'mental health problem'? More controversy might be welcome there as well. We do, however, detect a growing interest in and enthusiasm for research into bipolar disorder, and we hope that the publication of the first evidence-based national guidelines for the treatment of patients with bipolar disorder by the British Association of Psychopharmacology will be a step towards increasing awareness of the condition (Goodwin, 2003). Patients with bipolar disorder have every right to resent their Cinderella status, and every reason to want accurate early diagnosis and effective treatment.

\section{References}

Akiskal, H. S., Bourgeois, M. L., Angst, J., et al (2000) Reevaluating the prevalence of and diagnostic composition within the broad clinical spectrum of bipolar disorders. Journal of Affective Disorders, 59, S5-S30.

Akiskal, H. S. \& Mallya, G. (1987) Criteria for the 'soft' bipolar spectrum: treatment implications. Psychopharmacological Bulletin, 23, 68-73.

American Psychiatric Association (1994) Diagnostic and Statistical Manual of Mental Disorders (4th edn) (DSM-IV). Washington, DC: APA.

Angst, J. (1998) The emerging epidemiology of hypomania and bipolar II disorder. Journal of the Affective Disorders, 50, 143-151.

Baldessarini, R. J. (2000) A plea for integrity of the bipolar disorder concept. Bipolar Disorder, 2, 3-7.

Benazzi, F. (1998) Bipolar II depressed outpatients are frequent: a 423-case study. Canadian Journal of Psychiatry, 43,954 . 
Benazzi, F. \& Akiskal, H. S. (2003) Refining the evaluation of bipolar II: beyond the strict SCID-CV guidelines for hypomania. Journal of Affective Disorders, 73, 33-38.

Biederman, J. (2003) Pediatric bipolar disorder coming of age. Biological Psychiatry, 53, 931-934.

Biederman, J., Klein, R. G., Pine, D. S., et al (1998) Resolved: mania is mistaken for ADHD in prepubertal children. Journal of the American Academy of Child and Adolescent Psychiatry, 37, 1091-1096.

Carlson, G. A. (1998) Mania and ADHD: comorbidity or confusion. Journal of Affective Disorders, 51, 177-187.

Clement, S., Singh, S. P. \& Burns, T. (2003) Status of bipolar disorder research. Bibliometric study. British Journal of Psychiatry, 182, 148-152.

Department of Health (1999) National Framework for Mental Health: Modern Standards and Service Models for Mental Health. London: Department of Health.

Ghaemi, S. N., Boiman, E. E. \& Goodwin, F. K. (2000) Diagnosing bipolar disorder and the effect of antidepressants: a naturalistic study. Journal of Clinical Psychiatry, 61, 804-808.

Goodwin, G. M. (2002) Hypomania: what's in a name? British Journal of Psychiatry, 181, 94-95.

Goodwin, G. M. (2003) Evidence-based guidelines for treating bipolar disorder: recommendations from the British Association for Psychopharmacology. Journal of Psychopharmacology, 17, 149-173.

Hantouche, E. G., Akiskal, H. S., Lancrenon, S., et al (1998) Systematic clinical methodology for validating bipolar-II disorder: data in mid-stream from a French national multi-site study (EPIDEP). Journal of Affective Disorders, 50, 163-173

Harrington, R. \& Myatt, T. (2003) Is preadolescent mania the same condition as adult mania? A British perspective. Biological Psychiatry, 53, 961-969.

Kessler, R. C., Rubinow, D. R., Holmes, C., et al (1997) The epidemiology of DSM-III-R bipolar I disorder in a general population survey. Psychological Medicine, 27, 1079-1089.

Meltzer, H., Gatward, R., Goodman, R., et al (2000) Mental Health of Children and Adolescents in Great Britain. London: Stationery Office.

Murray, C. J. L. \& Lopez, A. D. (1997a) Alternative projections of mortality and disability by cause 1990 2020: Global Burden of Disease Study. Lancet, 349, 1498 1504.

Murray, C. J. L. \& Lopez, A. D. (1997b) Global mortality disability, and the contribution of risk factors: Global Burden of Disease Study. Lancet, 349, 1436-1442.

Perugi, G., Akiskal, H. S., Lattanzi, L., et al (1998) The high prevalence of 'soft' bipolar (II) features in atypical depression. Comprehensive Psychiatry, 39, 63-71.

Regier, D. A., Farmer, M. E., Rae, D. S., et al (1990) Comorbidity of mental disorders with alcohol and other drug abuse. Results from the Epidemiologic Catchment Area (ECA) Study. JAMA, 264, 2511-2518.

Smith, D. J. \& Blackwood, D. H. R. (2004) Depression in young adults. Advances in Psychiatric Treatment, 10,4-13.

Weller, R. A., Weller, E. B., Tucker, S. G., et al (1986) Mania in prepubertal children: has it been underdiagnosed? Journal of Affective Disorders, 11, 151-154.

\title{
SAFEGUARDS FOR YOUNG MINDS Young People and Protective Legislation
}

\author{
(Second edition)
}

\section{By Richard White, Anthony Harbour and Richard Williams. Edited by Richard Williams.}

This extremely successful title is concerned with the law as it applies to the welfare, protection and management of children and adolescents in mental health services. The second edition will be thoroughly updated. There will be an extra chapter on the new Human Rights Act as it applies to children and the law. Also, amendments to the Children Act 1989 consequent on legal judgements will be explained. A series of chapters will cover application of the Mental Health Act 1983 to young people, based on material developed from the College's successful training courses.

Due Dec 2003, Paperback, A4, 136pp, ISBN 190467102 0, Price £15.00

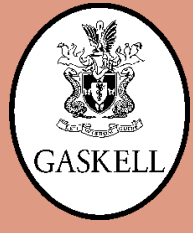

